\title{
Potent antitumor activity of oncolytic adenovirus expressing Beclin-1 via induction of autophagic cell death in leukemia
}

\author{
Yin Tong ${ }^{1, *}$, Liangshun You ${ }^{1, *}$, Hui Liu ${ }^{1}$, Lu Li $^{1}$, Haitao Meng ${ }^{1}$, Qijun Qian ${ }^{2}$, Wenbin \\ Qian ${ }^{1, *}$ \\ 1. Institute of Hematology, the First Affiliated Hospital, College of Medicine, Zhejiang University, P.R. China \\ 2. Laboratory of Viral and Gene Therapy, Eastern Hepatobiliary Surgery Hospital, Second Military Medical University, P.R. \\ China \\ * Contributed equally to this work \\ Correspondence to: Wenbin Qian, email: qianwenb@hotmail.com
}

Keywords: leukemia; oncolytic adenovirus; autophagy; Beclin-1; autophagic cell death; UVRAG

Received: May 15, 2013, Accepted: May 31, 2013, $\quad$ Published: June 3, 2013

This is an open-access article distributed under the terms of the Creative Commons Attribution License, which permits unrestricted use, distribution, and reproduction in any medium, provided the original author and source are credited.

\section{ABSTRACT:}

An attractive strategy among adenovirus-based oncolytic systems is to design adenoviral vectors to express pro-apoptotic genes, in which this gene-virotherapy approach significantly enhances tumor cell death by activating apoptotic pathways. However, the existence of cancer cells with apoptotic defects is one of the major obstacles in gene-virotherapy. Here, we investigated whether a strategy that combines the oncolytic effects of an adenoviral vector with simultaneous expression of Beclin-1, an autophagy gene, offers a therapeutic advantage for leukemia. A Beclin-1 CDNA was cloned in an oncolytic adenovirus with chimeric Ad5/11 fiber (SG511-BECN). SG511BECN treatment induced significant autophagic cell death, and resulted in enhanced cell killing in a variety of leukemic cell lines and primary leukemic blasts. SG511BECN effects were seen in chronic myeloid leukemia and acute myeloid leukemia with resistance to imatinib or chemotherapy, but exhibited much less cytotoxicity on normal cells. The SG511-BECN-induced autophagic cell death could be partially reversed by RNA interference knockdown of UVRAG, ATG5, and ATG7. We also showed that SG511-BECN strongly inhibited the growth of leukemic progenitors in vitro. In murine leukemia models, SG511-BECN prolonged the survival and decreased the xenograft tumor size by inducing autophagic cell death. Our results suggest that infection of leukemia cells with an oncolytic adenovirus overexpressing Beclin-1 can induce significant autophagic cell death and provide a new strategy for the elimination of leukemic cells via a unique mechanism of action distinct from apoptosis.

\section{INTRODUCTION}

Cancer virotherapy is a tumor-specific strategy, in which viruses are engineered to preferentially replicate in tumor cells and destroy it by lysis, either through targeted alterations in the cancer cells such as p53 mutation, viral deletion, tissue-specific transcriptional control or tumorspecific receptors [1-3]. Among available virotherapies, conditionally replicating adenoviruse (CRAd) is attractive because of its several attributes including lytic replication, efficient genome transfer, and excellent patient safety in clinical trials $[4,5]$. However, the previous clinical trials showed that in vivo efficacy of even CRAds is generally not sufficient for cancer therapy in clinic. Therefore, there are many attempts have been made to enhance the therapeutic index of CRAds. Two main strategies are currently being used to engineer CRAds to make them more selective and cytotoxic to tumor cells. The first approach is the creation of chimeric vectors, where the whole fiber or only the knob region is replaced with that of another serotype of adenovirus (Ad), which has led to decreased hepatotoxicity following virus administration 
Tabel 1: Clinical characteristics of patients

\begin{tabular}{|c|c|c|c|c|c|c|}
\hline patient & Sex/age & Diagnosis & $\begin{array}{l}\text { Blast, } \\
\%\end{array}$ & Cytogenetics & $\begin{array}{l}\text { Responses at time of } \\
\text { sampling }\end{array}$ & \begin{tabular}{|l|}
\multicolumn{2}{|l|}{ Responses } \\
after the \\
time of \\
sampling \\
\end{tabular} \\
\hline 1 & $\mathrm{M} / 51$ & CML-BP & 75 & $46 X Y, t(9 ; 22)(\mathrm{q} 34 ; \mathrm{q} 11)$ & prior treatment: Imatinib & $\mathrm{NA}$ \\
\hline 2 & $\mathrm{~F} / 65$ & CML-BP & 82.3 & 46XY,t(9;22)(q34;q11) & prior treatment: Imatinib & $\mathrm{NA}$ \\
\hline 3 & $\mathrm{M} / 42$ & CML-BP & 29 & 46XY,t(9;22)(q34;q11) & prior treatment: Hydroxyurea & $\mathrm{NA}$ \\
\hline 4 & $\mathrm{M} / 44$ & CML-CP & $<5$ & 46XY,t(9;22)(q34;q11) & newly diagnosed & NA \\
\hline 5 & $\mathrm{~F} / 18$ & CML-CP & $<5$ & 46XY,t(9;22)(q34;q11) & newly diagnosed & NA \\
\hline 6 & $\mathrm{M} / 68$ & CML-CP & $<5$ & 46XY,t(9;22)(q34;q11) & newly diagnosed & $\mathrm{NA}$ \\
\hline 7 & $\mathrm{M} / 56$ & CML-CP & $<5$ & 46XY,t(9;22)(q34;q11) & newly diagnosed & $\mathrm{NA}$ \\
\hline 8 & $\mathrm{M} / 61$ & CML-CP & $<5$ & 46XY,t(9;22)(q34;q11) & newly diagnosed & $\mathrm{NA}$ \\
\hline 9 & $\mathrm{M} / 55$ & CML-CP & $<5$ & 46XY,t(9;22)(q34;q11) & newly diagnosed & NA \\
\hline 10 & $\mathrm{~F} / 71$ & CML-CP & $<5$ & $46 X Y, t(9 ; 22)(q 34 ; q 11)$ & newly diagnosed & $\mathrm{NA}$ \\
\hline 11 & $\mathrm{~F} / 50$ & CML-CP & $<5$ & 46XY,t(9;22)(q34;q11) & newly diagnosed & $\mathrm{NA}$ \\
\hline 12 & $\mathrm{~F} / 57$ & CML-CP & $<5$ & 46XY,t(9;22)(q34;q11) & newly diagnosed & $\mathrm{NA}$ \\
\hline 13 & $\mathrm{M} / 51$ & CML-CP & $<5$ & 46XY,t(9;22)(q34;q11) & newly diagnosed & NA \\
\hline 14 & $\mathrm{M} / 35$ & CML-CP & $<5$ & 46XY,t(9;22)(q34;q11) & newly diagnosed & $\mathrm{NA}$ \\
\hline 15 & $\mathrm{~F} / 53$ & CML-CP & $<5$ & 46XY,t(9;22)(q34;q11) & newly diagnosed & $\mathrm{NA}$ \\
\hline 16 & $\mathrm{M} / 27$ & AML-M2 & 63 & $45 X,-Y, t(8 ; 21)(q 22 ; q 22)$ & newly diagnosed & no CR \\
\hline 17 & $\mathrm{M} / 66$ & AML-M5 & 46 & $46 X Y$ & newly diagnosed & no CR \\
\hline 18 & $\mathrm{~F} / 48$ & AML-M5 & 59 & $46 X Y$ & newly diagnosed & $\mathrm{CR}$ \\
\hline 19 & $\mathrm{M} / 20$ & AML-M2 & 54 & $46 X Y$ & newly diagnosed & $\mathrm{CR}$ \\
\hline 20 & $F / 24$ & AML-M4 & 50.5 & 46XX,t(11;12)(p15;q14) & newly diagnosed & no CR \\
\hline 21 & $\mathrm{M} / 24$ & AML-M3 & 83 & 46XY,t(15;17)(q22;q21) & newly diagnosed & CR \\
\hline 22 & M/19 & AML-M0 & 79 & \begin{tabular}{|l} 
44/45XY,complex \\
karyotype
\end{tabular} & relapsed & $\mathrm{CR}$ \\
\hline 23 & $\mathrm{~F} / 21$ & AML-M3 & 96 & 46XY,t(15;17)(q22;q21) & newly diagnosed & CR \\
\hline 24 & $\mathrm{M} / 62$ & AML-M2 & 88.5 & $46 X Y$ & newly diagnosed & no CR \\
\hline 25 & $\mathrm{~F} / 44$ & AML-M2 & 27 & $46 \mathrm{XX}$ & relapsed & no CR \\
\hline 26 & $\mathrm{~F} / 42$ & AML-M2 & 82 & $46 X X$ & relapsed & no CR \\
\hline 27 & $\mathrm{M} / 55$ & AML-M3 & 90 & 46XY,t(15;17)(q22;q21) & newly diagnosed & $\mathrm{CR}$ \\
\hline
\end{tabular}

attributed to less liver tropism, and increased infectivity of target tumor by coxsackie adenovirus receptor (CAR)independent transduction [6-9]. The clinical trials of chimeric CRAd show evidence of antitumor activity ranging from $61 \%$ to $67 \%$ and viral replication in the blood when the patients with advanced cancers were treated intratumorally or intravenously with chimeric viruses $[10,11]$. In addition, chimeric CRAds might be effective against cancer-initiating cells or cancer stem cells (CSC) [6,12]. For example, Ad5/3-Delta24, a capsid-modified CRAd, has been demonstrated to effectively kill $\mathrm{CD} 44^{+} \mathrm{CD} 24^{-/ \mathrm{low}}$ breast $\mathrm{CSCs}$ in vitro and in vivo [13]. Previously, we reported that a fiber-modified CRAd (Ad5/35) could permit CAR-independent cell entry and induce selective cytopathic effects in human leukemic cells [8]. Taken together, these studies suggest the possibility of clinical application of virotherapy for leukemia.

The second strategy is based on the insertion of therapeutic genes into the genome of a modified CRAd, thereby creating a so-called gene-virotherapy. Genevirotherapy shares the advantages of gene therapy and virotherapy, which can not only directly kill cancer cells by oncolysis, but also augment the copies of therapeutic genes by replication of the virus, resulting in longer transgene expression within tumors and potent activity against cancers [14-16]. Up to now, CRAds have been armed with a variety of transgenes that include tumor suppressor, pro-apoptotic, anti-angiogenic, immunomodulatory, and suicide genes $[17,18]$. We 
previously generated a series of E1B-55K deleted CRAds armed with different pro-apoptotic genes, such as tumor necrosis factor-related apoptosis-inducing ligand (TRAIL), p53, and interleukin-24, and demonstrated that the combination of pro-apoptotic or tumor suppressor genes and viral oncolysis yielded an additive cytotoxic effect on cancer cells. These viruses also proved more effective than the unarmed control vector at suppressing tumor growth in vivo, and prolonged survival in tumor or leukemia models $[8,19,20]$. However, cancer is a complex disorder associated with defects in multiple signaling pathways that confer resistance to apoptosis, suggesting the need for another innovative strategy [20,21]. Recent studies have demonstrated that autophagic cell death may serve as a novel way to eliminate tumor cells with defective apoptosis [22-26]. Therefore, we reasoned that arming CRAds with the genes inducing autophagic cell death could kill effectively cancer cells, especially cancer cells resistant to apoptosis, and represent an attractive prospect.

In this study, we combined the Beclin-1 gene therapy that induces autophagic cell death with SG511 vector (a new Ad5/11 fiber chimeric CRAd). The studies

A

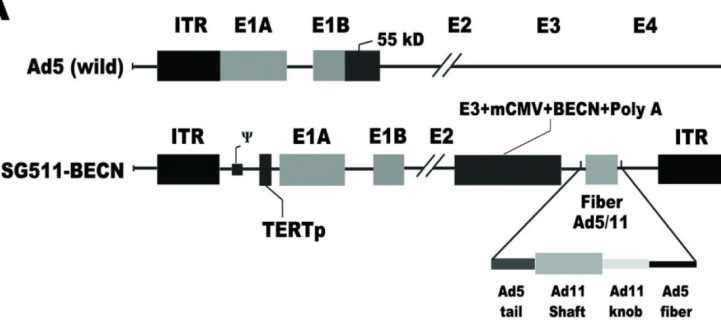

$\mathbf{B}$
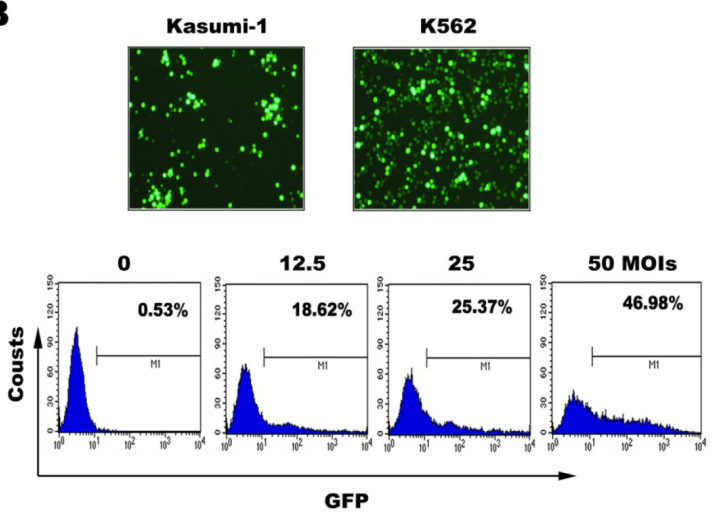

show that overexpression of Beclin-1 significantly enhanced the killing effect of the virus on leukemia cell lines and primary leukemic cells, in which cytotoxic activity of the parental virus without Beclin-1 gene was weak overall. In addition, Beclin-1 expression also strongly inhibited the growth of leukemic progenitors and prolonged the survival of leukemic xenograft-bearing animals by inducing autophagic cell death. From these findings, it is clear that the strategy of inducing autophagic cell death can be successfully linked with oncolytic viral approaches in the quest for an efficacious therapeutic approach for treating leukemias.

\section{RESULTS}

\section{Construction and characterization of a chimeric, Beclin-1-armed CRAd}

Schematic structures of the genomes of SG511BECN, along with wild Ad5, are shown in Figure 1A. The Beclin-1 transgene was engineered into the $\mathrm{E} 3$ region

C

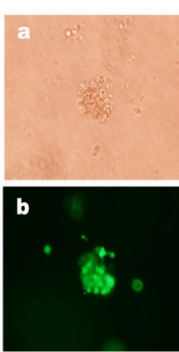

D

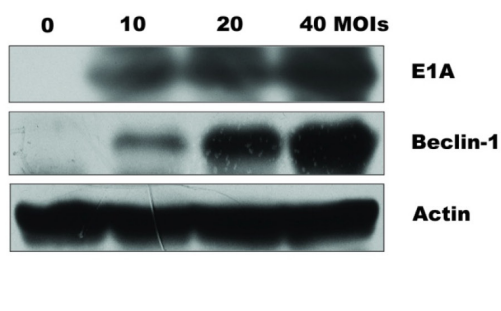

$\mathbf{E}$
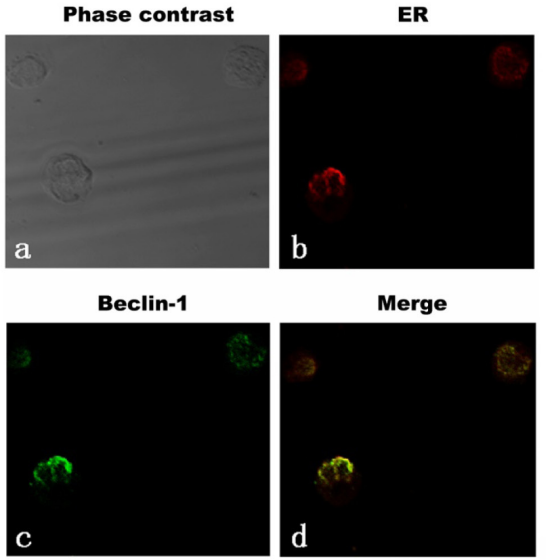

Figure 1: Schematic diagram of adenoviral constructs and CRAd infectivity in leukemic cells. (A) Compared to wild-type Ad5, SG511-BECN contains a human telomerase reverse transcriptase (hTERT) promoter-controlled E1 expression cassette in forward orientation, an E1B 55-kDa deletion, and Beclin-1 transgene in E3 region. The fiber was modified by an Ad5/11 chimeric fiber. (B) Kusumi-1 and K562 cells were infected with 50 MOI of SG511-GFP for $24 \mathrm{~h}$ and then observed under a fluorescence microscope (200×) (top panel). K562 cells were treated with the indicated amount of the virus for $24 \mathrm{~h}$ and then collected for analysis by FACS (bottom panel). (C) Bone marrow cells obtained from a patient with AML were infected with SG511-GFP at an MOI of 50, and then cultured for 5 days in colony culture assay. Photographs were viewed under a light microscope and fluorescence microscope, respectively (400×). (D) Beclin- 1 and E1A expression was determined by Western blotting of K562 cells infected with SG511-BECN at the indicated concentrations for $48 \mathrm{~h}$. Actin was Western blotted for equal loading. (E) Following SG511-BECN treatment for 48 h, Beclin-1 (green) and ER (red) in K562 cells were detected by confocal immunofluorescence microscopy. Representative data of three experiments is shown. 
A

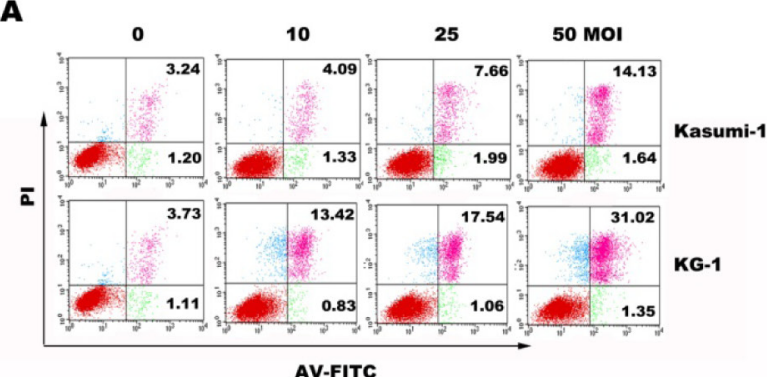

D

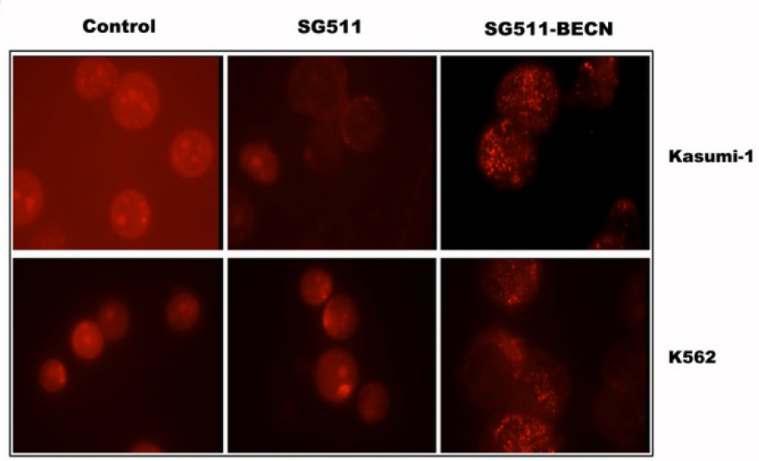

$\mathbf{B}$
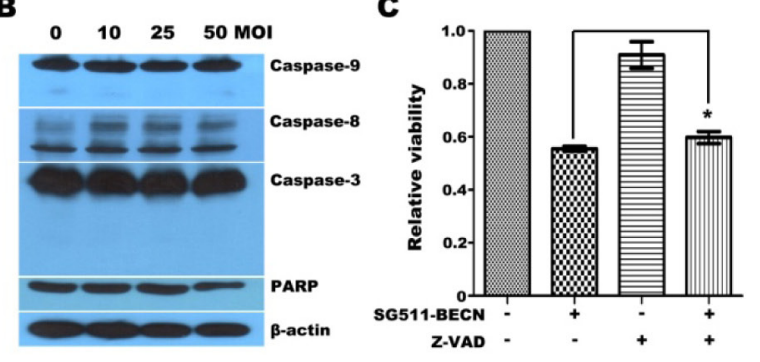

$\mathbf{E}$
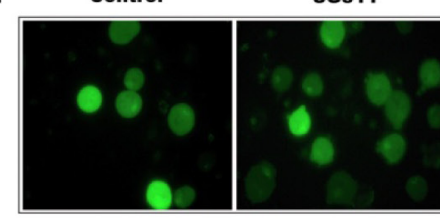

SG511-BECN

F Control Ad5

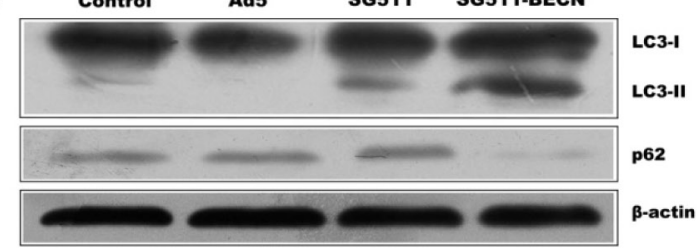

G
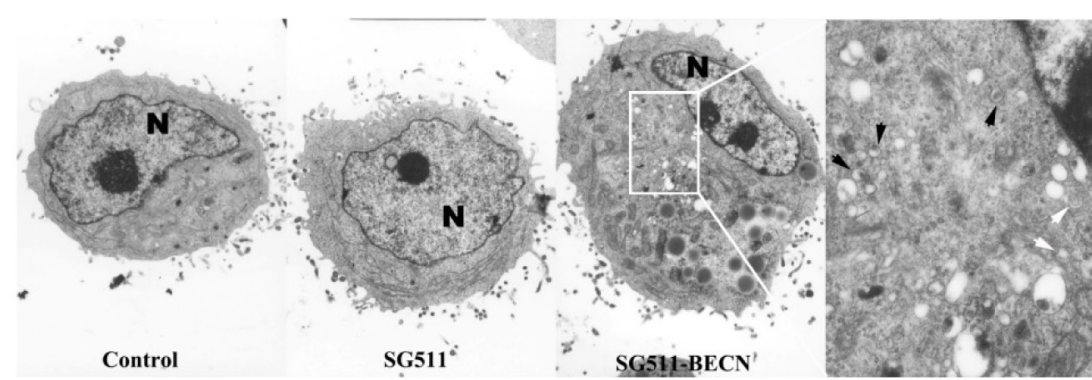

H

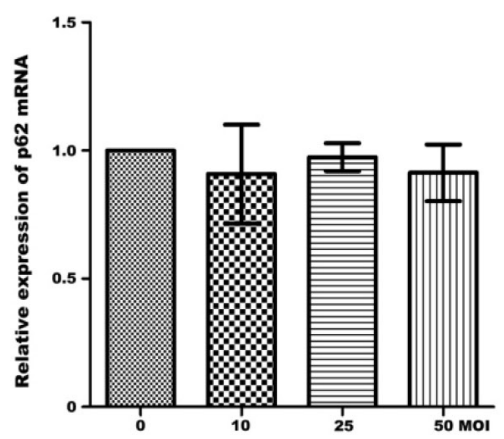

I

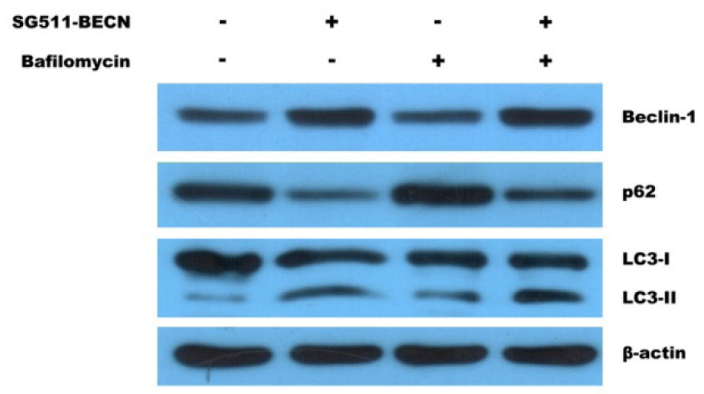

Figure 2: SG511-BECN virus induced cell death involves autophagy in leukemia cells. (A) Kasumi-1 and KG-1 cells were treated with SG511-BECN at the doses indicated. Two days later, cell death was assessed by FACS analysis of annexin V-and PI staining. (B) K562 cells were treated with SG511-BECN at the indicated doses for $48 \mathrm{~h}$ before cell lysates were immunoblotted for the protein indicated. (C) K562 cells were incubated with SG511-BECN, or incubated with z-VAD (10 iM) and SG511-BECN for 72 h. Then, cell viability was determined by an MTT assay. *represents $P>0.05$ (D) Formation of AVOs was determined after leukemic cells were infected with or without SG511, or SG511-BECN at an MOI of 50 for 48 h. (E) Formation of GFP-LC3 vacules (dots) was determined after K562 cells were stably transfected with GFP-LC3 vector and treated with 50 MOI of SG511 or SG511-BECN for 48 h. (F) K562 cells were infected with or without the indicted viruses (50 MOI) for $48 \mathrm{~h}$. The cell lysates were harvested and analyzed by Western blotting using antiLC3 and anti-p62 antibodies. (G) Kasumi-1 cells treated with SG511 and SG511-BECN, respectively and observed under TEM $(\times 4200)$. There are two types of vacuole in the cytoplasm of SG511-BECN-treated cells: dense multilamellar bodies (white arrows) and inclusion bodies (black arrows). A representative of two separate experiments is shown. (H) qRT-PCR analysis monitoring p62 expression in K562 cells treated with SG511-BECN. Bars represent SD. (I) K562 cells were infected with 50 MOI SG511-BECN, alone or in combination with $20 \mathrm{nM}$ BafA1. Total cell lysates were immunoblotted with anti-LC3, anti-p62, or anti-Actin antibodies, as indicated. 
of the genome under the control of cytomegalovirus promoter. K562 and Kasumi-1 were used to evaluate the infectious efficiency of SG511 that is a similar virus without Beclin-1. CRAd containing the GFP gene (SG511-GFP)-infected cells was photographed using a fluorescence microscopy. As shown in Figure 1B, the leukemic cells were easily transduced by the virus. FACS analysis showed that the proportion of GFP-positive K562 cells increased in a dose-dependent manner after SG511GFP infection. To determine the infection efficiency of SG511 on primary leukemic cells, the blasts from 7 AML patients were treated with SG511-GFP. The average portion of GFP-expressing cells was $68.77 \%$ at 2 days post-infection $(\mathrm{MOI}=50)$ (Supplementary Fig. 1A). Moreover, leukemic blasts from an AML patient were treated with SG511-GFP (MOI=50), and colony forming unit-leukemia (CFU-L) was assessed in methylcellulose culture. The cells within CFU-L showed bright green fluorescence dots (Fig. 1C), suggesting that this chimeric CRAd could effectively infect leukemic progenitor cells.

To investigate whether the infection of leukemia cells with SG511-BECN can produce Beclin-1 protein, K562 cells were exposed to the virus for $48 \mathrm{~h}$ and subjected to Western blot analysis. Results showed the dose-dependent increase of Beclin-1 and adenovirus E1A expression, respectively (Fig. 1D). To examine whether expression of Beclin-1 could hinder replication of CRAd, a progeny assay was performed in the supernatants of K562 cells infected with SG511 and SG511-BECN, respectively. Results demonstrated that the yield of virus
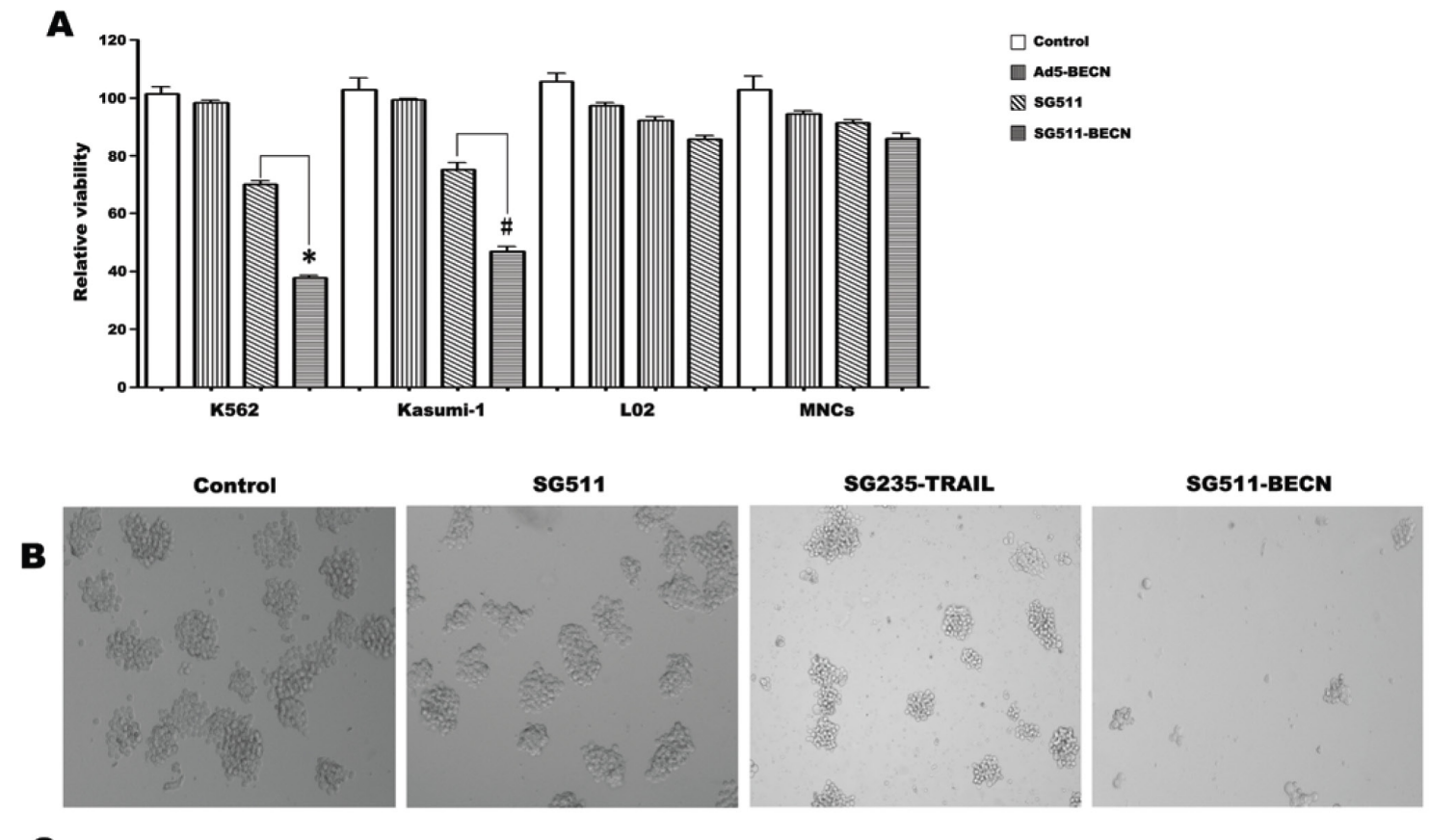

C
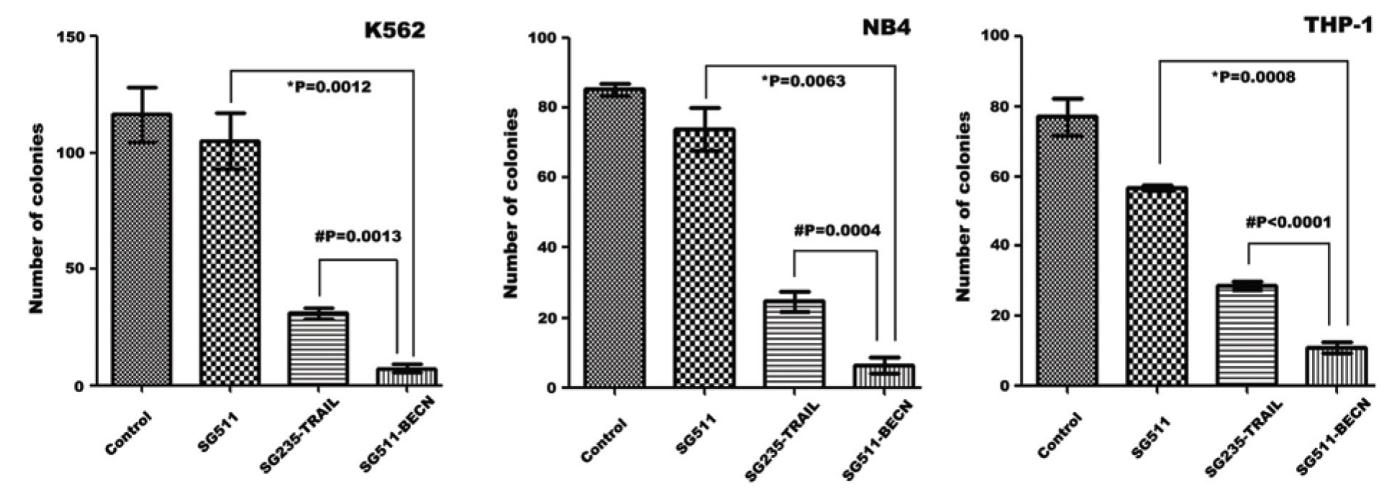

Figure 3: Superior efficacy of SG511-BECN compared with the CRAd expressing TRAIL. (A) Leukemic cells $\left(2 \times 10^{4}\right)$, human MNCs, and L02 cells were treated with Ad5-BECN, SG511, or SG511-BECN at an MOI of 50 for $72 \mathrm{~h}$ before analysis of cell viability (MTT assay). The results represent means $\pm \mathrm{SD}$ of three independent experiments. ${ }^{*} P<0.0001$, vs $\mathrm{SG} 511$, \# $P=0.0007$, vs $\mathrm{SG} 511$. (B) K562 cells were treated with the indicated viruses at 50 MOI and colonies were observed on day 7 under a light microscope. (C) K562, NB4, and THP-1 cells were infected with or without SG511, SG235-TRAIL, and SG511-BECN at an MOI of 50, respectively. The cells were then plated in methylcellulose medium. After incubation for 7 days, colonies (more than 50 cells) were scored. Data represent means \pm SD for separate experiments. \#SG511-BECN vs SG235-TRAIL, *SG511-BECN vs SG511. 
production was equivalent in the two treatment groups (data not shown). Next we examined the subcellular distribution of Beclin-1 in the infected K562 cells using antibodies to costain Beclin-1 and Calreticulin. Confocal immunofluorescence analysis revealed the colocalization of Beclin-1 protein with Calreticulin, an endoplasmic reticulum (ER) protein (Fig. 1E), consistent with the results of previous studies [27,28].

\section{SG511-BECN induced autophagic cell death in leukemia cells}

Based on the overexpression of Beclin-1 in SG511BECN-infected cells, we sought to determine whether treatment of cells with the virus results in autophagic cell death. Figure 2A shows that SG511-BECN caused a dosedependent non-apoptotic cell death that is characteristic of annexin $\mathrm{V}^{+}$and $\mathrm{PI}^{+}$[25]. Furthermore, significant activation of caspase pathway was not observed (Fig. 2B). Co-treatment the broad caspase inhibitor z-VAD- fmk did not block SG511-BECN-induced inhibition of cellular viability, suggesting that this virus activates caspase-independent cell death (Fig. 2C). Autophagy is characterized by the formation of AVOs and the location of microtubule-associated protein LC3 on autophagosomes [23]. Thus, we detected autophagy by measuring: (1) formation of AVOs by FACS; (2) electron microscopy of AVOs; (3) formation of GFP-LC3-labeled vacuoles by transfection and fluorescent microscopy; and (4) conversion of LC3-I to LC3-II by Western blot. As expected, SG511-BECN significantly induced AVO formation in Kasumi-1 and K562 cells over a 48-hour time course, whereas the SG511 vector did not (Fig. 2D). Furthermore, SG511-BECN also resulted in a significant formation of GFP-LC3-labled vacuoles (Fig. 2E). Strong up-regulation of LC3-II and degradation of p62 was observed upon SG511-BECN treatment, but not in PBSor wild Ad5-treated cells; however a weak up-regulation of LC3-II was observed in the cells infected with SG511 (Fig. 2F). In agreement with those results, EM showed many autophagic vacuoles in the cells treated with SG511-
A

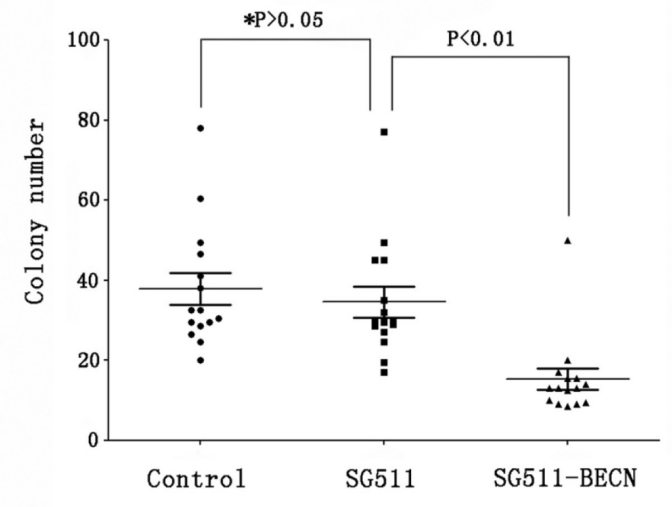

B

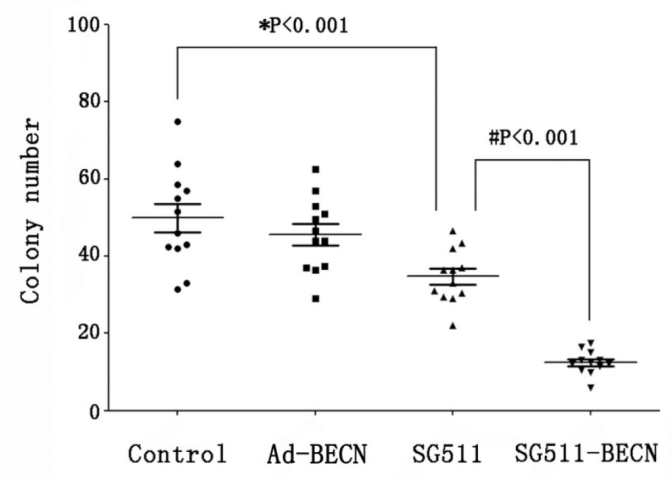

C

D

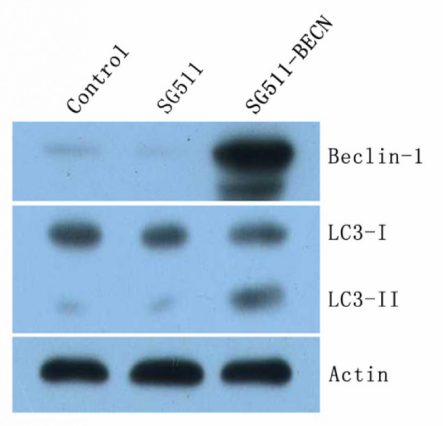

E

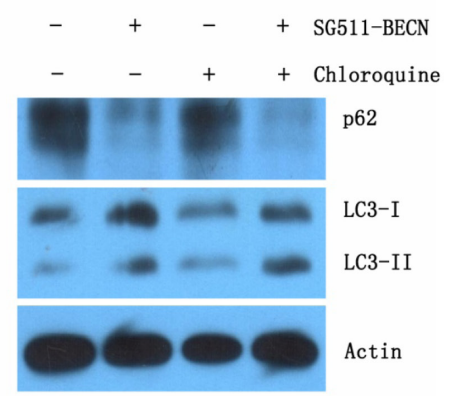

Figure 4: SG511-BECN induces autophagy in primary leukemic cells to preferentially inhibit CFU-L formation. (A) Freshly isolated leukemia cells from CML patients $(\mathrm{n}=15)$ were cultured in methylcellulose medium in the presence of SG511, or SG511BECN at an MOI of 50. After 12 days, colonies were scored. *, $P>0.05$ vs. Control; \# $P<0.01$ vs. SG511. (B) Leukemic cells from 12 patients with AML were treated with the indicated vectors at an MOI of 50 before analysis of effects on colony formation. ${ }^{*}, P<0.001 v s$. Control; \# $P<0.001$ vs. SG511. (C) Bone marrow cells obtained from 4 healthy volunteers were treated with the indicated viruses, and colonies were counted after 12 days. For all panels, values represent the mean of experiments in triplicate. (D) The primary leukemic cells from a CML patient in blast crisis (case 1) were infected with the indicated viruses at an MOI of 50, cell lysate was immunoblotted with anti-Beclin-1, anti-LC3, and anti-â-actin antibodies at day 2 of the experiment. (E) The primary blasts were treated with SG511-BECN (50 MOI), or SG511-BECN plus chloroquine (25 iM) for $48 \mathrm{~h}$. Autophagic flux was determined using Western blotting. 
BECN. In contrast, these vacuoles were not seen in the PBS- or SG511-treated cells (Fig. 2G). Quantitative realtime PCR analysis showed that level of p62 mRNA was not significantly down regulated by SG511-BECN (Fig. $2 \mathrm{H})$. We next monitored the autophagic flux by assessing the ratio between LC3-II of p62 levels. Treatment with BafA1, an autophagy inhibitor that blocks autolysosome formation, enhanced SG511-BECN-induced LC3-II accumulation, while the SG511-BECN-induced reduction of p62 was partially prevented by BafA1 (Fig. 2I), confirming the autophagy-mediated p62 degradation. Together, these findings led us to conclude that SG511BECN could effectively induce autophagic cell death in leukemic cells.
A
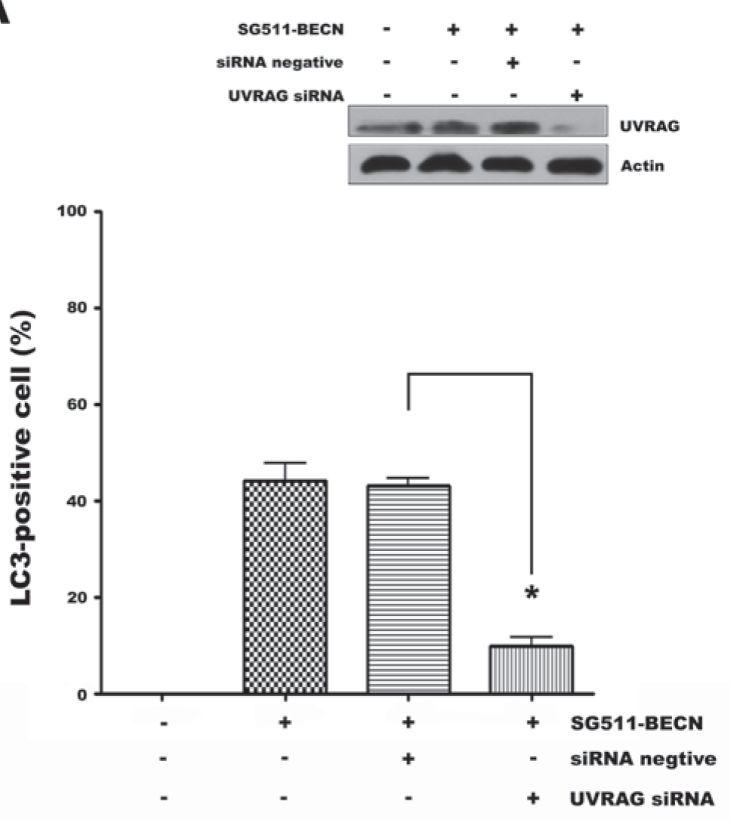

B

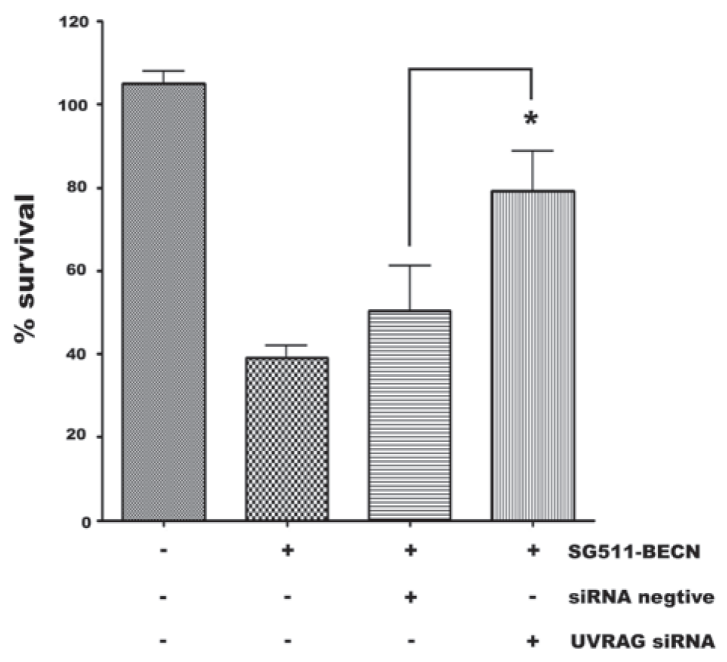

C
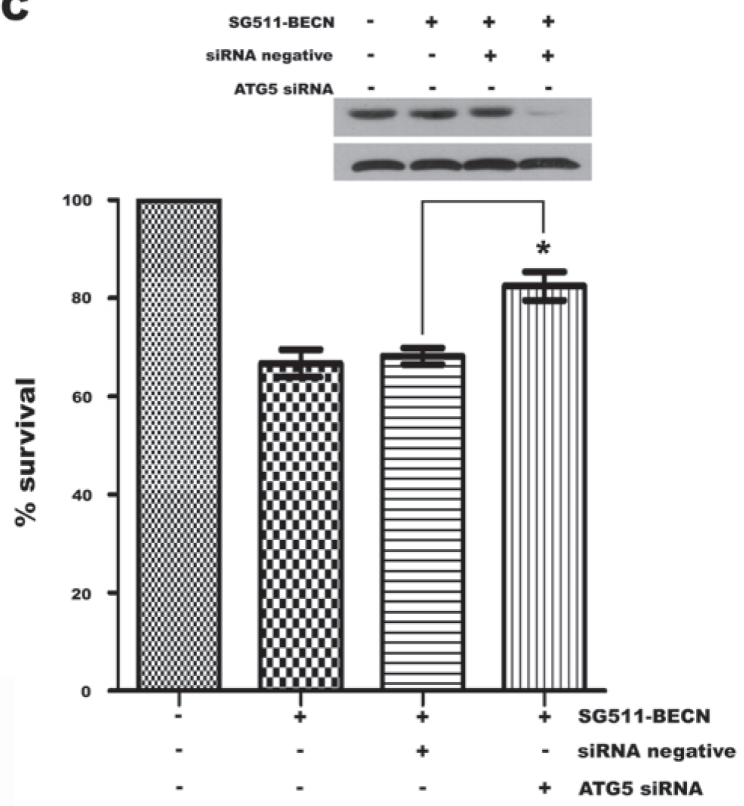

D

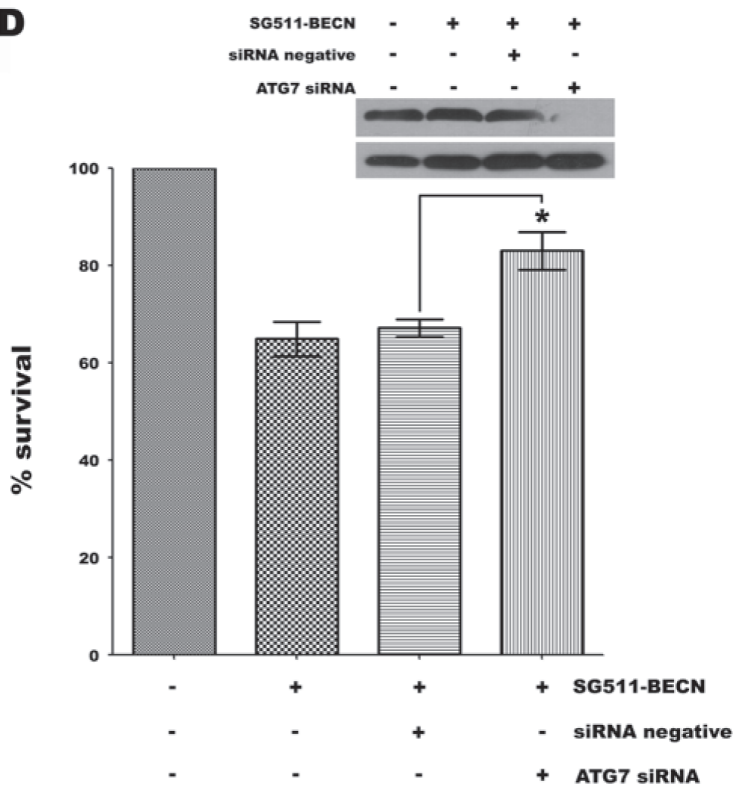

Figure 5: siRNA-mediated UVRAG, ATG5, or ATG7 knockdown reverses suppressive effects of SG511-BECN. (A) Expression of autophagy gene UVRAG was silenced by siRNA in K562 cells containing GFP-LC3, and LC3-positive vesicle-containing cells were determined after treatment with SG511-BECN for $48 \mathrm{~h}$. UVRAG expression was detected by Western blotting of K562 cells. â-actin was used as protein loading control (insert). (B) Experimental conditions as in (A). Cell viability was assessed by an MTT assay. *Represents $P<0.001$ compared to control. Standard error was calculated from three independent experiments. (C) K562 cells were transfected with $100 \mathrm{nM}$ ATG5 siRNA for $48 \mathrm{~h}$, and then treated with SG511-BECN for $48 \mathrm{~h}$. The indicated protein level was analyzed by Western blot (insert). In parallel, cell viability was assessed by an MTT assay ( $P=0.0019)$. (D) ATG7 protein level and viability of K562 cells were determined after transfection with ATG7 siRNA as indicated in (C). *represents $P<0.0029$. 


\section{Superior activity of SG511-BECN against leukemia cells in vitro}

To investigate the increased cytotoxic effect of SG511-BECN compared with SG511 and Ad-BECN, leukemia cells and human normal cells were infected with different vectors. At $72 \mathrm{~h}$ after viral infection, cell viability was determined by the MTT assay. Results showed that SG511-BECN had a remarkable cell killing effect compared with the other viruses in each leukemia cell line. The cell killing effect of SG511-BECN was about 2 times higher than that of SG511. In contrast, minimal cytotoxic effect was detected in normal cells (Fig. 3A). Importantly, CFU-L formation was almost completely eliminated when the SG511-BECN was used at an MOI of 50 (Fig. 3B). However, SG511 did not show a significant inhibitory effect on colony growth of K562 cells. Therefore, these findings suggest that the antileukemia activity of SG511BECN is superior to that of SG511 vector in vitro.
Our previous data showed that SG235-TRAIL has an enhanced antileukemic therapeutic effect by induction of apoptosis [8]. In the present study, we compared the antileukemic activity of SG511-BECN with that of SG235-TRAIL. K562, NB4, and THP-1 cells were infected with the indicated viruses at an MOI of 50, and then colony assays were performed (Fig. 3C). Treatment with SG511 slightly inhibited colony formation of these cells; by contrast, fewer colonies formed after treatment with SG235-TRAIL, and there was an additional marked decrease in CFU-L formation upon treatment with SG511BECN. To further assess whether enhanced antitumor activity of SG511-BECN is specific for leukemic cells, cytotoxicity of different viruses against human solid tumor cells (Hep3B, Hela, and T42) was determined by the violet assay. The results showed that cell killing by SG511BECN was more effective than by SG511 (Supplementary Fig. 1B), suggesting the activity of SG511-BECN against a broad spectrum of human cancers.
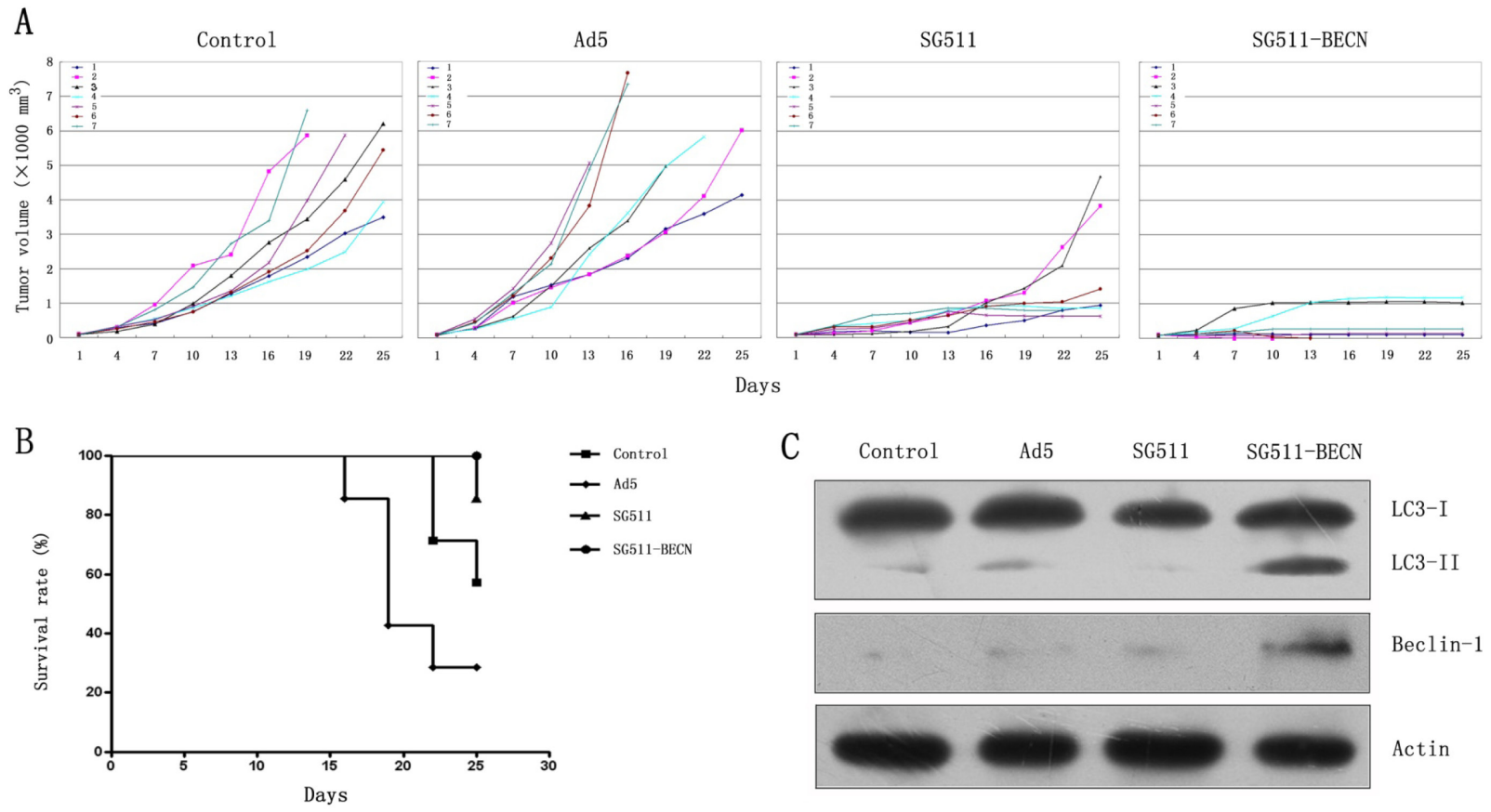

D
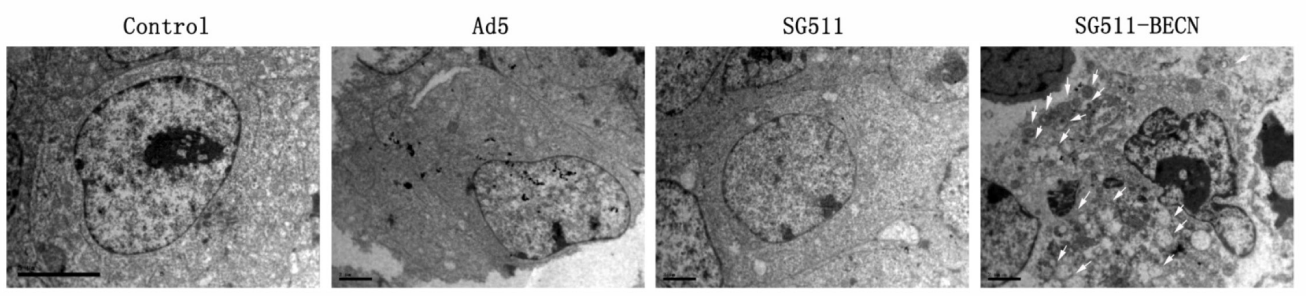

Figure 6: Antileukemic efficacy of SG511-BECN in established K562 tumors in vivo. Mice bearing subcutaneous K562 xenografts $(n=8)$ were randomized to receive one of the following intratumoral injections on 5 consecutive days: PBS, Ad5, SG511, and SG511-BECN. (A) Time courses of changes in tumor volume in each group $(n=7)$ are shown. (B) Survival curve analysis. The percentage of surviving mice was determined by monitoring the death of mice over a period of 25 days. Mice treated with SG511-BECN shows significant survival advantage over mice treated with other groups $(P=0.0072)$. (C) Tumor tissues were obtained on day 5 after treatment with different viruses, and Beclin-1 expression and the level of LC3-II was determined by Western blotting. The expression of â-actin was used as loading control. (D) Electron microscopy images were taken of tumor tissues $(3700 \times)$. Autophagic vacuoles are denoted by arrow. 


\section{SG511-BECN effectively suppresses colony formation of primary CML cells from patients with imatinib resistant disease and AML cells from relapsed disease}

To determine whether SG511-BECN virus is effective against primary leukemia cells, we tested the clonogenic capacity of primary blasts isolated from patients with CML in chronic phase or myeloid blast crisis with imatinib-resistant disease, and AML patients in newly diagnosed or relasped disease. The characteristics of these cases are shown in Table 1. Primary cells were exposed to the different viruses at an MOI of 50 and subjected to blast colony assays. Results showed that exposure of primary cells to SG511 virus had relatively little effect on clonogenic potential. However, in both AML (Fig. 4A) and CML (Fig. 4B), SG511-BECN resulted in a pronounced reduction in colony formation compared to SG511 ( $P<0.01$, and $P<0.001$, respectively). In contrast, the ability of normal specimens $(\mathrm{n}=4)$ to form colonies was not substantially affected by treatment with SG511 or SG511-BECN, respectively (Fig. 4C). Further, a dramatic increase in the Beclin-1 expression and conversion of LC3-I to LC3-II was observed in primary cells treated with SG511-BECN (Fig. 4D). Using chloroquine, an alkalinizing lysosomotropic drug, autophagic flux was determined in primary leukemic cells obtained from a CML patient. Results showed that SG511-BECN-induced LC3-II accumulation was apparently augmented in cells exposed to chloroquine (Fig. 4E), suggesting efficient autophagic flux. Collectively, these data suggest that SG511-BECN significantly impairs leukemic but not normal hematopoietic progenitor-cell function.

\section{Interaction of Beclin-1 with UVRAG is essential for the induction of autophagic cell death by SG511-BECN}

As UVRAG-mediated activation of the Beclin-1PI(3)KC3 complex promotes autophagy and suppresses the proliferation of cancer cells [29], we examined the effect of siRNA against UVRAG on autophagic cell death induced by SG511-BECN to demonstrate indirectly whether overexpression of Beclin-1 contributes to cell death of leukemia. siRNA was used to reduce endogenous UVRAG expression in K562 cells infected with SG511BECN, which resulted in a remarkable reduction of UVRAG protein level (Fig. 5A). A significantly decreased number of LC3-positive cells was observed upon siRNA treatment $(P<0.001$; Fig. $5 \mathrm{~A})$. Moreover, knockdown of UVRAG also resulted in reversal of the suppressive effects of SG511-BECN $(P<0.05)$ (Fig. 5B). Together, these data suggest that autophagy induced by overexpression of Beclin-1 is an important mechanism by which SG511BECN generates antileukemic activity, and the interaction of Beclin-1 with UVRAG is essential, at least in part, for the induction of autophagic cell death. Next, we targeted key components of the autophagic machinery using specific siRNAs and evaluated their effects on SG511BECN-induced cell death. Selective knockdown of either ATG5 (Fig. 5C) or ATG7 (Fig. 5D) resulted in reversal of the suppressive effects of SG511-BECN on cell viability.

\section{Enhanced Anti-leukemia effect of SG511-BECN in vivo}

To assess the therapeutic efficacy of SG511 versus SG511-BECN against leukemic cells in vivo, K562 xenograft model was established. Figure 6A shows that CRAd-treated tumors were substantially delayed in their growth. Ad5 virus did not show any antileukemia activity. At 22 days post treatment, xenografts of mice treated with SG511 reached an average tumor volume of 1256 $\mathrm{mm}^{3}$. In contrast, mean tumor volume was $388 \mathrm{~mm}^{3}$ in the mice treated with SG511-BECN. Importantly, complete regression of the tumors was observed in two of seven mice treated with SG511-BECN, but not in SG511-treated mice. The Kaplan-Meier survival curve shows that all animals treated with SG511-BECN were still viable, while $85.7 \%$ of the SG511-treated mice survived. In comparison, only $57.1 \%$ of control mice and $28.6 \%$ of Ad5-treated mice were alive in the same time period (Fig. 6B), suggesting that CRAd expressing Beclin-1 confers significant survival benefits $(P=0.0072)$. To verify induction of autophagy in vivo, the overexpression of Beclin-1 and LC3-I to LC3II conversion in tumors were detected by Western blot on day 5 after viral injection. Notable overexpression of Beclin-1 protein and conversion of LC3-I to LC3II were found in the SG511-BECN-treated tumor (Fig. $6 \mathrm{C}$ ), confirming the role of autophagy in inhibiting tumor growth. Furthermore, TEM analyses of tumors showing the appearance of autophagic vesicles in SG511-BECNtreated group also supported this conclusion (Fig. 6D).

\section{DISCUSSION}

Although gene-virotherapy by arming CRAds with pro-apoptotic genes is a well-established modality for various cancers, appearance of cancer cells resistant to apoptosis is one of the major concerns. Accumulating evidence indicates that autophagic cell death plays an important role in the generation of anticancer activity in apoptosis defective cells [23-25]. Autophagy also has been implicated as the main mechanism by which some antileukemia agents produce their antileukemic activities [30-33]. For example, arsenic trioxide was showed to induce autophagic cell death in leukemic cell lines and AML progenitors, which could be reversed by knockdown of Beclin-1 or Atg7 [31]. Interestingly, induction of autophagy not only mediates cell death induced by 
dexamethasone in lymphoid leukemia, but also is required for leukemic cells to overcome glucocorticoid resistance $[30,33]$. These studies raise the possibility that genes that induce autophagy could act as sensitizers of leukemia cells to the killing effects of oncolytic virus. The present study shows that SG511-BECN, a chimeric CRAd armed with Beclin-1, effectively kills a variety of leukemic cells through viral oncolysis, while production of Beclin-1 by the infected cell significantly augments the therapeutic effects. We have validated induction of autophagy by our Beclin-1-armed viruses, as indicated by the formation of the autophagic vesicles detected by four independent approaches: TEM, AVO staining, LC3-I to LC3-II conversion by Western blotting and LC3 translocation to vacuoles in GFP-LC3-transfected K562 cells, respectively. Also, the autophagic flux assays revealed that SG511BECN induced autophagy. Consistent with these results, we found that ATG5 and ATG7 knockdown rescued the cells from SG511-BECN-induced growth inhibition. Because UVRAG, a Beclin-1-interacting protein, associates with the Beclin-1-Bcl-2-PI(3)KC3 multiprotein complex, where UVRAG and Beclin-1 interdependently induce autophagy [29], reversal of the antileukemic effects of SG511-BECN by knockdown of UVRAG also demonstrated that autophagic cell death contribute to the enhanced cytotoxicity of the virus against leukemia cells.

Human Beclin-1 is the functional homologue of yeast Vps30/Apg6 gene that interacts with class $\square$ PI3K complex and participates in autophagic vesicle nucleation [34-36]. Beclin-1 gene knockout in mice was demonstrated to cause a marked increase in epithelial and hematopoietic malignancies $[37,38]$. The deletion and reduced expression of Beclin-1 was found in various types of cancer cells [39]. In patients with hepatocellular carcinoma and gastric cancers, reduced Beclin-1 expression is associated with a poor prognosis [40,41], while high expression is associated with favourable prognosis for salivary carcinoma and lymphoma patients $[42,43]$. Overall, the data suggest that Beclin-1 is a tumour suppressor gene. An earlier study showed that transfection of breast cancer cells that lack detectable endogenous Beclin-1 protein with Beclin-1 gene inhibited cell growth and tumor clonigenicity in vitro and in vivo [34]. As previous studies demonstrated that gene-virotherapy resulted in an augment expression of transgenes due to replication of the virus within cancer cells $[16,17]$, the important question arises: whether integrating Beclin-1 gene therapy into an oncolytic virus elicit strong antileukemia activity? We revealed that a chimeric CRAd plus Beclin-1 achieved superior antileukemic effects and survival compared with group treated with SG511 virus alone. Notably, SG511-BECN also effectively kills leukemic progenitors evidenced by almost complete inhibition of CFU-L formation. These results support the observation that Ras-induced expression of Noxa and Beclin-1 promotes autophagic cell death and reduces clonogenic survival
[44]. Furthermore, treatment with SG511-BECN induced complete elimination of established tumor xenografts in a mouse leukemia model. Together, these results suggest that CRAds armed with therapeutic transgenes such as Beclin-1 could eradicate leukemia stem cells although the exact effects of SG511-BECN on CD34+ leukemic stem cells has not been determined.

The relationship between autophagy and cancer, however, is still unclear $[22,39,45]$. Recently, numerous studies shed light onto different aspects of this relationship. Firstly, autophagy activation promotes survival of cancer cells under stress, including cytotoxic agents and different signaling pathway inhibitors [20,25,46,47]. This protective autophagic process has also been observed in AML cells $[46,48]$. For example, erlotinib, an epidermal growth factor receptor inhibitor, can induce autophagy in various AML cell lines by inhibiting the phosphorylation mTOR targets [48]. In several studies, hyperactivation of basal autophagy was shown to be important for the therapeutic resistance of malignancy. In support of this hypothesis, a study showed that ATG12 was upregulated in breast cancer cells and knockdown of the ATG12 gene fully suppressed the refractoriness of the cancer cells to treatment with molecularly targeted agents [49]. Recently, accumulating evidence indicates that the function of autophagy in tumor is dynamic with both protumorigenic and tumor suppressive roles which depend on stage of cancer progression, cellular context and tissue of origin [45]. In fact, induction of autophagic cell death has been demonstrated in several types of tumors with defective apoptosis. Akar et al. [50] revealed that siRNA of Bcl2 in MCF-7 breast cancer cells deficient for caspase 3 inhibited cell growth and colony formation, and resulted in cell death by autophagy but not apoptosis. For leukemia, in vivo experiments showed that mammalian target of rapamycin inhibitor RAD001 increased survival of leukemic engrafted animals via induction of autophagy, but not apoptosis [51]. We and others have previous shown that CRAd-mediated TRAIL gene therapy for leukemia and breast cancer resulted in significant increases of cell killing and suppression of tumor growth by inducing apoptosis $[8,52]$. An interesting finding of this work is that SG511-BECN produced antitumor effects in a CFU-L formation assay that were superior to that observed by using SG235-TRAIL. Notably, we showed that efficacy of SG511-BECN was not affected by patient characteristics, such as chromosome aberrations, and imatinib-, or chemotherapy-resistance making it potentially useful in refractory or relapse leukemia patients too. Crucially, SG511-BECN treatment failed to inhibit not only proliferation of human normal MNCs and hepatic L02 cells but also normal hematopoietic colony formation, consistent with previous reports in which oncolytic adenovirus has the capability to selectively replicate in tumor cells not in normal cells in a p53-dependent [53] or -independent manner [54], suggesting that the combination 
selectively kills leukemia cells while sparing normal cells. Taken together, our results thus provide strong evidence that Beclin-1 gene-virotherapy is an alternative promising antileukemia therapeutic strategy.

Intravascular delivery of CRAds is required for effectively treating leukemia. Previous studies suggested that Ad-based virotherapy or genetherapy is associated with several limitations during systemic administration. These limitations include the immune attack against adenoviruses by complement, cytokine or most critically neutralizing antibodies, which is account for the virus toxicity and limited efficacy, and the sequestration of the virus by liver cells $[55,56]$. However, it was suggested that genetic modifications made to CRAds using tumorspecific promoters including human telomerase reverse transcriptase (hTERT) and fiber modifications might allow the escape of adenovirus from preexisting antibodies, and the selective infection of the viruses for tumor cells, but not of normal cells $[55,57,58]$. In the present study, the effects of SG511-BECN on human normal liver cell line L02 were investigated, no significant toxicity in L02 cells was observed, suggesting that this chimeric oncolytic virus carrying hTERT promoter might reduce hepatotoxicity. However, additional work will be needed to assess the therapeutic potential and immunogenicity of SG511BECN during intravascular therapy.

In conclusion, the data presented herein show for the first time that, by introducing the Beclin-1 gene into the oncolytic adenoviral backbone, antileukemia activity of the virus can be significantly improved, leading to a complete elimination of leukemia xenografts and prolonged survival of tumor-bearing mice. Thus, CRAd with Ad5/11 fibers, expressing the Beclin-1 gene may offer a novel promising gene-virotherapy for the treatment of leukemia via a unique mechanism of action distinct from apoptosis.

\section{MATERIALS AND METHODS}

\section{Normal and leukemia patient samples, cell lines, and reagents}

Bone marrow samples were obtained from healthy controls and patients with chronic myeloid leukemia $(C M L ; n=15)$ and acute myeloid leukemia (AML; $n=12)$. The mononuclear cells (MNCs) were isolated by FicollHypaque density gradient centrifugation after informed consent was obtained using guidelines approved by the Ethics Committee of Zhejiang University. Human AML cell lines NB4, THP-1 and CML cell line K562 were purchased from the American Type Culture Collection (ATCC; Manassas, VA, USA), and AML cell lines Kasumi-1 and KG-1 was kindly provided by Prof. S Chen (Shanghai Jiaotong University, Shanghai, China) and Prof. R Xu (Zhejiang University, Hangzhou, China), respectively. L-02 cell line, a normal human liver cell line, was purchased from the Shanghai Cell Collection (Shanghai, China). The cell lines were authenticated by comparing immunophenotype, karyotype, and molecular marker. All the cell lines were used within 6 months after documentation, and cultured as described earlier [8]. The pancaspase inhibitor z-VAD-fmk was purchased from $\mathrm{R}$ \& D (Minneapolis, MN, USA), Bafilomycin A1 (BafA1) and chloroquine were purchased from Sigma (St Louis, MO, USA).

\section{Construction of recombinant viruses}

The complete cDNA sequence of Beclin-1 gene was amplified by PCR by using the upstream primer (5'CCG GAA TTC ACC ATG GAA GGG TCT AAG ACG TCC AAC-3') and downstream primer (5'-ACG CGT CGA CTT ATC ATT TGT TAT AAA ATT GTG AGG$\left.3^{\prime}\right)$. The synthetic DNA was released with EcoR $I$ and Sal I (New England Biolabs, Beverley, MA, USA) and ligated into plasmid pENTR-12 to generate pENTR12BECN. After sequence confirmation, pENTR12-BECN construct was then recombined using the LR reaction (Invitrogen, Carlsbad, CA, USA) into the pPE11 to form pPE11-BECN. pPE11 is an adenovirus packaging plasmid construced by replacing Ad5 fiber with Ad5/11 chimeric fiber [3]. Finally, the pPE11-BECN was transfected into HEK293 cells using Lipofectamine 2000 (Invitrogen) together with plasmid pSG500 [2]. The obtained CRAds was named as SG511-BECN. Enhanced green fluorescence protein (GFP) gene was cloned into SG511 to construct SG511-GFP and SG235-TRAIL was constructed as described previously [8]. Ad-BECN, a replicationdeficient adenovirus expressing Beclin-1, was provided by Prof. Q Qian (Second Military Medical University, Shanghai, China).

\section{Cell proliferation assay}

For cell proliferation assays using 3-(4,5-dimethylthiazol-2-yl) -2,5-diphenyltetrazolium bromide (MTT; Sigma), cells were seeded in 96-well plates at a density of $2 \times 10^{4} / \mathrm{ml}$ in the presence or absence of Ad-BECN, SG511, or SG511-BECN at a concentration of 50 MOI. After $48 \mathrm{~h}, 20$ il of MTT solution $(5 \mathrm{mg} / \mathrm{ml})$ was added to each well. The samples were incubated at $37^{\circ} \mathrm{C}$ for $4 \mathrm{~h}$ and the absorbance was measured at $570 \mathrm{~nm}$ by spectrophotometry.

\section{Flow Cytometric Analysis}

After treatment with SG511-BECN for $48 \mathrm{~h}$, cells were harvested and washed with PBS buffer containing 
$5 \mathrm{mmol} / \mathrm{L}$ EDTA. And then incubated at $37^{\circ} \mathrm{C}$ for $30 \mathrm{~min}$. Cell death was determined by staining cells with annexin V-FITC and propidium iodide (PI) using annexin V-FITC apoptosis detection kit (BD Pharmingen, San Diego, CA, USA) followed by analysis on a BD FACSCalibur flow cytometer. Expression of the GFP gene was also assessed by the FACSCalibur.

\section{Detection of autophagosome formation with acridine orange}

To detect the presence of acidic vesicular organelles (AVOs), leukemic cells were treated with SG511, and SG511-BECN, respectively. After $48 \mathrm{~h}$, the cells were stained with the vital dye acridine orange $(1 \mathrm{ig} / \mathrm{mL}$; Molecular Probes, Eugene, OR, USA) and then examined immediately by fluorescence microscope (IX71; Olympus, Tokyo, Japan) with a red filter (excitation $560 \mathrm{~nm}$, emission $645 \mathrm{~nm}$ ).

\section{Staining autophagosomes with GFP-LC3}

K562 cells stably expressed GFP-LC3 were established as described previously [20]. The cells were treated with SG511 or SG511-BECN at an MOI of 50 for $48 \mathrm{~h}$. The fluorescence of GFP-LC3 was viewed under a fluorescent microscope and photographs were taken. The cells with GFP-LC3 vacuoles (autophagosomes) were counted by image analysis using ImageJ software (National Institutes of Health, Bethesda, MD, USA).

\section{Cellular localization studies}

K562 cells were infected with or without SG511BECN at MOI of 50 for $48 \mathrm{~h}$ and cells were washed with PBS, fixed in the $0.1 \%$ poly-L-lysine-treated slides with $4 \%$ paraformaldehyde, permeabilized by $0.1 \%$ Triton $\mathrm{X}-100$ and then incubated with anti-Beclin-1 (Novus Biologicals, Littleton, CO, USA), and calreticulin (Merck, Calbiochem, Darmstadt, Germany) at $4^{\circ} \mathrm{C}$ for overnight. After washing with PBS, the slides were incubated with Alexa Fluor 488 and Alexa Fluor 568 (Invitrogen), and examined for visualization under an Olympus confocal microscope (FV1000).

\section{Transfection of UVRAG siRNA vector}

K562 cells expressing GFP-LC3 were transiently transfected with human UVRAG-siRNA, ATG5 siRNA, or ATG7 siRNA, respectively, as per the manufacturer's instructions, using shRNA Plasmid Transfection Reagent (Santa Cruz Biotechnology, Santa Cruz, CA, USA) or Lipofectamine Transfection Reagent (Invitrogen). Control-siRNA (Santa Cruz) was used as negative control.
After transfection, cells were cultured for $48 \mathrm{~h}$, and treated with SG511-BECN, and the viability of cells, protein expression of the targeted genes, and GFP-LC3 vacuoles were analyzed.

\section{Western blot Analyses}

Western blot analyses were performed as described previously $[8,20]$. The primary antibodies used in this study were purchased from: anti-Beclin-1 (Novus Biologicals), anti-LC3 (Novus Biologicals), anti-p62, anti-caspase-3, -9, and -8, anti-PARP, anti-ATG5, and anti-ATG7 (Cell signaling, Beberly, MA, USA), anti-E1A (BD PharMingen), anti-UVRAG (Sigma), and anti-â-actin (Santa Cruz).

\section{Real-time RT-PCR}

Total RNA was isolated and quantitative real-time PCR (qRT-PCR) was performed as previously described [25] using the primers: 5'-TGG TAG GAA CCC GCT ACA AGT-3' (forward) and 5'-CCC GAA GTG TCC GTG TTT C-3' (reverse) for human p62 and 5'-ATG GGG AAG GTG AAG GTC G-3' (forward) and 5'-GGG TCA TTG ATG GCA ACA ATA TC-3' (reverse) for GAPDH.

\section{Colony forming analysis}

Leukemic cell lines, MNCs from the patients with AML, CML or healthy controls were infected with or without the indicated viruses (50 MOI) and seeded in triplicate in a mixture containing $1.35 \%$ methylcellulose (Sigma) in Iscove's modified Dulbecco's medium (IMDM; Sigma) supplemented with $20 \%$ fetal bovine serum (Hyclone, Logan UT, USA) and $10^{-4}$ M 2-Mercaptoethanol (Sigma). For colony assay of bone marrow cells, $3 \mathrm{U} /$ $\mathrm{mL}$ recombinant human (rh) erythropoietin, $50 \mathrm{ng} / \mathrm{mL} \mathrm{rh}$ stem cell factor, $30 \mathrm{ng} / \mathrm{mL}$ rh granulocyte macrophagecolony-stimulating factor, and $10 \mathrm{ng} / \mathrm{mL}$ rh interleukin-3 (Peprotech, Rocky Hill, NJ, USA) were added to the methylcellulose medium. The colonies were evaluated under a microscope on day 12 of culture. In contrast, leukemic cell lines were seeded in cytokine-free mixture as described previously [26], and the colonies were counted on day 7 .

\section{Transmission electron microscope}

Tumors or leukemic cells were harvested after treatment with the viruses, and fixed with $2.5 \%$ phosphatebuffered gluteraldehyde, and then postfixed in $1 \%$ phosphatebuffered osmium tetroxide, embedded in Spurr's resin. The ultrathin sections $(0.12 \mathrm{im})$ were cut, double stained with uranyl acetate and lead citrate. Representative 
areas were chosen and viewed with a Philips TECNA10 transmission electron microscope (TEM) at accelerating voltage of $80 \mathrm{kV}$.

\section{Animal experiments}

All animal experiments were approved by the Institutional Animal Care and Use Committee, Zhejiang University. Female severe combined immunodeficient mice (3- to 4-weeks-old) were purchased from Experimental Animal Center of the Chinese Academy of Sciences (Shanghai, China). K562 cells $\left(1 \times 10^{7}\right)$ were injected subcutaneously into the lower right flank of mice. When the s.c. nodules grew and reached a volume of $80-100 \mathrm{~mm}^{3}$, the mice were randomly assigned to three treatment groups (Ad, SG511, and SG511-BECN) and one control group $(n=8)$. A daily dose of $2 \times 10^{8}$ plaqueforming units of different adenoviruses in $100 \mathrm{il} \mathrm{of} \mathrm{PBS,}$ or PBS alone, was administrated intratumorally for 5 days. Tumor growth was monitored and measured every 3 days with a Vernier caliper and tumor volume was calculated as previously described [8]. On day 5 after treatments, one mouse from each group was randomly selected, and humanely killed. Tumors were harvested for Western blotting and TEM analysis.

\section{Statistics}

The significance of differences between groups was assessed by Student's unpaired two-tailed $t$ test. The antileukemia effect in vivo was evaluated by plotting survival curves according to the Kaplan-Meier method, and survivals among treatments groups were compared using the log-rank test. A $P$-value of $<0.05$ was considered significant.

\section{Authors' Contributions}

Conception and design: W.B. Qian

Development of methodology: Q. J. Qian, L. Li

Acquisition of data (provided animals, acquired and managed patients, provided facilities, etc.): Y. Tong, L.S. You, H. Liu, H.T. Meng, W.B. Qian

Analysis and interpretation of data (e.g., statistical analysis, biostatistics, computational analysis): L.S. You, W.B. Qian

Writing, review, and/or revision of the manuscript: Y. Tong, W.B. Qian

Study supervision: W.B. Qian

\section{Disclosure of Potential Conflicts of Interest}

No potential conflicts of interest disclosed.

\section{Grant Support}

This work was supported by National Natural Science Foundation of China grants (No 81070419) to W.B. Qian, Zhejiang Provincial Natural Science Foundation of China (No R2090392) to W.B. Qian, and Funds of Science Technology Department of Zhejiang Province (No 2012C13021-2 and 2012C37103) to W.B. Qian and C.M. Yang.

\section{REFERENCES}

1. Eager RM, Nemunaitis J. Clinical development directions in oncolytic viral therapy. Cancer Gene Ther. 2011;18(5):305317.

2. Zhang Q, Chen G, Peng L, Wang X, Yang Y, Liu C, Shi W, Su C, Wu H, Liu X, Wu M, Qian Q. Increased safety with preserved antitumoral efficacy on hepatocellular carcinoma with dual-regulated oncolytic adenovirus. Clin Cancer Res. 2006;12(21):6523-6531.

3. Jin H, Lv S, Yang J, Wang X, Hu H, Su C, Zhou C, Li J, Huang Y, Li L, Liu X, Wu M, Qian Q. Use of microRNA Let-7 to control the replication specificity of oncolytic adenovirus in hepatocellular carcinoma cells. PLoS One. 2011;6(7):e21307.

4. Vasey PA, Shulman LN, Campos S, Davis J, Gore M, Johnston S, Kirn DH, O’Neill V, Siddiqui N, Seiden MV, Kaye SB. Phase I trial of intraperitoneal injection of the E1B-55-kd-gene-deleted adenovirus ONYX-015 (d11520) given on days 1 through 5 every 3 weeks in patients with recurrent/refractory epithelial ovarian cancer. J Clin Oncol. 2002;20(6):1562-1569.

5. Kimball KJ, Preuss MA, Barnes MN, Wang M, Siegal GP, Wan W, Kuo H, Saddekni S, Stockard CR, Grizzle WE, Harris RD, Aurigemma R, Curiel DT, Alvarez RD. A phase I study of a tropism-modified conditionally replicative adenovirus for recurrent malignant gynecologic diseases. Clin Cancer Res. 2010;16(21):5277-5287.

6. Short JJ, Curiel DT. Oncolytic adenoviruses targeted to cancer stem cells. Mol Cancer Ther. 2009;8(8):2096-2102.

7. Rivera AA, Davydova J, Schierer S, Wang M, Krasnykh V, Yamamoto M, Curiel DT, Nettelbeck DM. Combining high selectivity of replication with fiber chimerism for effective adenoviral oncolysis of CAR-negative melanoma cells. Gene Ther. 2004;11(23):1694-1702.

8. Jin J, Liu H, Yang C, Li G, Liu X, Qian Q, Qian W. Effective gene-viral therapy of leukemia by a new fiber chimeric oncolytic adenovirus expressing TRAIL: in vitro and in vivo evaluation. Mol Cancer Ther. 2009;8(5):13871397.

9. Ranki T, Hemminki A.Serotype chimeric human adenoviruses for cancer gene therapy. Viruses. 2010;2(10):2196-2212.

10. Koski A, Kangasniemi L, Escutenaire S, Pesonen S, Cerullo 
V, Diaconu I, Nokisalmi P, Raki M, Rajecki M, Guse K, Ranki T, Oksanen M, Holm SL, Haavisto E, Karioja-Kallio A, Laasonen L, et al. Treatment of cancer patients with a serotype 5/3 chimeric oncolytic adenovirus expressing GMCSF. Mol Ther. 2010;18(10):1874-1884.

11. Pesonen S, Nokisalmi P, Escutenaire S, Särkioja M, Raki M, Cerullo V, Kangasniemi L, Laasonen L, Ribacka C, Guse K, Haavisto E, Oksanen M, Rajecki M, Helminen A, Ristimäki A, Karioja-Kallio A, et al. Prolonged systemic circulation of chimeric oncolytic adenovirus Ad5/3Cox2L-D24 in patients with metastatic and refractory solid tumors. Gene Ther. 2010;17(7):892-904.

12. Cripe TP, Wang PY, Marcato P, Mahller YY, Lee PW. Targeting cancer-initiating cells with oncolytic viruses. Mol Ther. 2009;17(10):1677-1682.

13. Eriksson M, Guse K, Bauerschmitz G, Virkkunen P, Tarkkanen M, Tanner M, Hakkarainen T, Kanerva A, Desmond RA, Pesonen S, Hemminki A. Oncolytic adenoviruses kill breast cancer initiating CD44+CD24-/low cells. Mol Ther. 2007;15(12):2088-2093.

14. Hermiston T. Gene delivery from replication-selective viruses: arming guided missiles in the war against cancer. J Clin Invest. 2000;105(9):1169-1172.

15. Liu XY, Qiu SB, Zou WG, Pei ZF, Gu JF, Luo CX, Ruan HM, Chen Y, Qi YP, Qian C. Effective gene-virotherapy for complete eradication of tumor mediated by the combination of hTRAIL (TNFSF10) and plasminogen k5. Mol Ther. 2005;11(4):531-541.

16. Dong F, Wang L, Davis JJ, Hu W, Zhang L, Guo W, Teraishi F, Ji L, Fang B. Eliminating established tumor in nu/nu nude mice by a tumor necrosis factor-alpha-related apoptosis-inducing ligand-armed oncolytic adenovirus. Clin Cancer Res. 2006;12(17):5224-5230.

17. Cody JJ, Douglas JT. Armed replicating adenoviruses for cancer virotherapy. Cancer Gene Ther. 2009;16(6):473-488.

18. Wong HH, Lemoine NR, Wang Y. Viruses. Oncolytic Viruses for Cancer Therapy: Overcoming the Obstacles. Viruses. 2010;2(1):78-106.

19. He X, Liu J, Yang C, Su C, Zhou C, Zhang Q, Li L, Wu H, Liu X, Wu M, Qian Q.5/35 fiber-modified conditionally replicative adenovirus armed with p53 shows increased tumor-suppressing capacity to breast cancer cells. Hum Gene Ther. 2011;22(3):283-292.

20. Yang C, Tong Y, Ni W, Liu J, Xu W, Li L, Liu X, Meng H, Qian W. Inhibition of autophagy induced by overexpression of mda-7/interleukin-24 strongly augments the antileukemia activity in vitro and in vivo.Cancer Gene Ther. 2010;17(2):109-119.

21. Mashima T, Tsuruo T.Defects of the apoptotic pathway as therapeutic target against cancer. Drug Resist Updat. 2005;8(6):339-343

22. Chen N, Karantza V.Autophagy as a therapeutic target in cancer. Cancer Biol Ther. 2011;11(2):157-168.

23. Chen Y, McMillan-Ward E, Kong J, Israels SJ, Gibson SB.
Oxidative stress induces autophagic cell death independent of apoptosis in transformed and cancer cells. Cell Death Differ. 2008;15(1):171-182.

24. Høyer-Hansen M, Bastholm L, Mathiasen IS, Elling F, Jäättelä M. Vitamin D analog EB1089 triggers dramatic lysosomal changes and Beclin 1-mediated autophagic cell death. Cell Death Differ.2005;12(10):1297-1309.

25. Qian W, Liu J, Jin J, Ni W, Xu W. Arsenic trioxide induces not only apoptosis but also autophagic cell death in leukemia cell lines via up-regulation of Beclin-1. Leuk Res. 2007;31(3):329-339.

26. Carew JS, Nawrocki ST, Kahue CN, Zhang H, Yang C, Chung L, Houghton JA, Huang P, Giles FJ, Cleveland JL. Targeting autophagy augments the anticancer activity of the histone deacetylase inhibitor SAHA to overcome Bcr-Ablmediated drug resistance. Blood. 2007;110(1):313-322.

27. Liang XH, Yu J, Brown K, Levine B. Beclin 1 contains a leucine-rich nuclear export signal that is required for its autophagy and tumor suppressor function. Cancer Res. 2001;61(8):3443-3449.

28. Perrotta I, Carito V, Russo E, Tripepi S, Aquila S, Donato G. Macrophage autophagy and oxidative stress: an ultrastructural and immunoelectron microscopical study. Oxid Med Cell Longev. 2011;2011:282739.

29. Liang C, Feng P, Ku B, Dotan I, Canaani D, Oh BH, Jung JU. Autophagic and tumour suppressor activity of a novel Beclin1-binding protein UVRAG. Nat Cell Biol. 2006;8(7):688-699.

30. Laane E, Tamm KP, Buentke E, Ito K, Kharaziha P, Oscarsson J, Corcoran M, Björklund AC, Hultenby K, Lundin J, Heyman M, Söderhäll S, Mazur J, Porwit A, Pandolfi PP, Zhivotovsky B, et al. Cell death induced by dexamethasone in lymphoid leukemia is mediated through initiation of autophagy. Cell Death Differ. 2009;16(7):10181029.

31. Goussetis DJ, Altman JK, Glaser H, McNeer JL, Tallman MS, Platanias LC.Autophagy is a critical mechanism for the induction of the antileukemic effects of arsenic trioxide. $\mathrm{J}$ Biol Chem. 2010;285(39):29989-29997.

32. Heidari N, Hicks MA, Harada H. GX15-070 (obatoclax) overcomes glucocorticoid resistance in acute lymphoblastic leukemia through induction of apoptosis and autophagy. Cell Death Dis. 2010;1:e76.

33. Bonapace L, Bornhauser BC, Schmitz M, Cario G, Ziegler U, Niggli FK, Schäfer BW, Schrappe M, Stanulla M, Bourquin JP. Induction of autophagy-dependent necroptosis is required for childhood acute lymphoblastic leukemia cells to overcome glucocorticoid resistance. J Clin Invest. 2010;120(4):1310-1323.

34. Liang XH, Jackson S, Seaman M, Brown K, Kempkes B, Hibshoosh H, Levine B. Induction of autophagy and inhibition of tumorigenesis by beclin-1. Nature. 1999;402(6762):672-676.

35. Kihara A, Kabeya Y, Ohsumi Y, Yoshimori T. Beclin- 
phosphatidylinositol 3-kinase complex functions at the trans-Golgi network.EMBO Rep. 2001;2(4):330-335.

36. He C, Levine B. The beclin 1 interactome. Curr Opin Cell Biol. 2010 Apr;22(2):140-9.

37. Qu X, Yu J, Bhagat G, Furuya N, Hibshoosh H, Troxel A, Rosen J, Eskelinen EL, Mizushima N, Ohsumi Y, Cattoretti G, Levine B. Promotion of tumorigenesis by heterozygous disruption of the beclin-1 autophagy gene. J Clin Invest. 2003;112(12):1809-1820.

38. Yue Z, Jin S, Yang C, Levine AJ, Heintz N. Beclin-1, an autophagy gene essential for early embryonic development, is a haploinsufficient tumor suppressor. Proc Natl Acad Sci U S A. 2003;100(25):15077-15082.

39. Dalby KN, Tekedereli I, Lopez-Berestein G, Ozpolat B. Targeting the prodeath and prosurvival functions of autophagy as novel therapeutic strategies in cancer. Autophagy. 2010;6(3):322-329.

40. Ding ZB, Shi YH, Zhou J, Qiu SJ, Xu Y, Dai Z, Shi GM, Wang XY, Ke AW, Wu B, Fan J. Association of autophagy defect with a malignant phenotype and poor prognosis of hepatocellular carcinoma. Cancer Res. 2008;68(22):91679175.

41. Zhou WH, Tang F, Xu J, Wu X, Yang SB, Feng ZY, Ding YG, Wan XB, Guan Z, Li HG, Lin DJ, Shao CK, Liu Q. Low expression of Beclin 1, associated with high Bcl$\mathrm{xL}$, predicts a malignant phenotype and poor prognosis of gastric cancer. Autophagy. 2012; 8(3):389-400.

42. Huang JJ, Zhu YJ, Lin TY, Jiang WQ, Huang HQ, Li ZM. Beclin 1 expression predicts favorable clinical outcome in patients with diffuse large B-cell lymphoma treated with R-CHOP. Hum Pathol. 2011;42(10):1459-1466.

43. Liang LZ, Ma B, Liang YJ, Liu HC, Zheng GS, Zhang TH, Chu M, Xu PP, Su YX, Liao GQ. High expression of the autophagy gene Beclin-1 is associated with favorable prognosis for salivary gland adenoid cystic carcinoma. J Oral Pathol Med. 2012;41(8):621-629.

44. Elgendy M, Sheridan C, Brumatti G, Martin SJ. Oncogenic Ras-induced expression of Noxa and Beclin-1 promotes autophagic cell death and limits clonogenic survival. Mol Cell 2011;42(1):23-35.

45. Mancias JD, Kimmelman AC. Targeting autophagy addiction in cancer. Oncotarget. 2011;2(12):1302-1306.

46. Chiarini F, Lonetti A, Teti G, Orsini E, Bressanin D, Cappellini A, Ricci F, Tazzari PL, Ognibene A, Falconi M, Pagliaro P, Iacobucci I, Martinelli G, Amadori S, McCubrey JA, Martelli AM. A combination of temsirolimus, an allosteric mTOR inhibitor, with clofarabine as a new therapeutic option for patients with acute myeloid leukemia. Oncotarget. 2012;3(12):1615-1628.

47. Criollo A, Chereau F, Malik SA, Niso-Santano M, Mariño G, Galluzzi L, Maiuri MC, Baud V, Kroemer G. Autophagy is required for the activation of NFкB. Cell Cycle. 2012;11(1):194-199.

48. Boehrer S, Galluzzi L, Lainey E, Bouteloup C, Tailler M,
Harper F, Pierron G, Adès L, Thépot S, Sébert M, Gardin C, de Botton S, Fenaux P, Kroemer G. Erlotinib antagonizes constitutive activation of SRC family kinases and mTOR in acute myeloid leukemia. Cell Cycle. 2011;10(18):31683175 .

49. Cufí S, Vazquez-Martin A, Oliveras-Ferraros C, Corominas-Faja B, Urruticoechea A, Martin-Castillo B, Menendez JA. Autophagy-related gene 12 (ATG12) is a novel determinant of primary resistance to HER2-targeted therapies: utility of transcriptome analysis of the autophagy interactome to guide breast cancer treatment. Oncotarget. 2012;3(12):1600-1614.

50. Akar U, Chaves-Reyez A, Barria M, Tari A, Sanguino A, Kondo Y, Kondo S, Arun B, Lopez-Berestein G, Ozpolat B. Silencing Bcl-2 expression by small interfering RNA induces autophagic cell death in MCF-7 breast cancer cells. Autophagy. 2008;4(5):669-679.

51. Crazzolara R, Cisterne A, Thien M, Hewson J, Baraz R, Bradstock KF, Bendall LJ. Potentiating effects of RAD001 (Everolimus) on vincristine therapy in childhood acute lymphoblastic leukemia. Blood. 2009;113(14):3297-3306.

52. Guo W, Zhu H, Zhang L, Davis J, Teraishi F, Roth JA, Stephens C, Fueyo J, Jiang H, Conrad C, Fang B. Combination effect of oncolytic adenovirotherapy and TRAIL gene therapy in syngeneic murine breast cancer models. Cancer Gene Ther. 2006;13(1):82-90.

53. Bischoff JR, Kirn DH, Williams A, Heise C, Horn S, Muna M, Ng L, Nye JA, Sampson-Johannes A, Fattaey A, McCormick F. An adenovirus mutant that replicates selectively in p53-deficient human tumor cells. Science 1996; 274(5286):373-376.

54. Dix BR, Edwards SJ, Braithwaite AW. Does the antitumor adenovirus ONYX-015/d11520 selectively target cells defective in the p53 pathway? J Virol 2001; 75 (12):54435447.

55. Thaci B, Ulasov IV, Wainwright DA, Lesniak MS. The challenge for gene therapy: innate immune response to adenoviruses. Oncotarget. 2011;2(3):113-121.

56. Donnelly O, Vile R, Pandha H, Harrington K, Melcher A. The hitchhiker's guide to virotherapy. Oncotarget. 2012;3(8):735-736.

57. Kishimoto H, Aki R, Urata Y, Bouvet M, Momiyama M, Tanaka N, Fujiwara T, Hoffman RM. Tumor-selective, adenoviral-mediated GFP genetic labeling of human cancer in the live mouse reports future recurrence after resection. Cell Cycle. 2011;10(16):2737-2741.

58. Lin WH, Yeh SH, Yang WJ, Yeh KH, Fujiwara T, Nii A, Chang SS, Chen PJ. Telomerase-specific oncolytic adenoviral therapy for orthotopic hepatocellular carcinoma in HBx transgenic mice. Int J Cancer. 2013;132(6):14511462.Z. Msi-1 is a predictor of survival and a novel therapeutic target in colon cancer. Ann Surg Oncol. 2011; 18(7):2074-2083. 